\title{
Influence of Polymer Reagents in the Drilling Fluids on the Efficiency of Deviated and Horizontal Wells Drilling
}

\author{
Tianle Liu ${ }^{1}$, Ekaterina Leusheva ${ }^{2}$, Valentin Morenov ${ }^{2}{ }^{(D}$, Lixia Li ${ }^{1}{ }^{*}$, Guosheng Jiang ${ }^{1}$, \\ Changliang Fang ${ }^{1}$, Ling Zhang ${ }^{1}$, Shaojun Zheng ${ }^{1}$ and Yinfei Yu ${ }^{1}$ \\ 1 Faculty of Engineering, China University of Geosciences, Wuhan 430074, China; \\ liutianle2008@163.com (T.L.); jianggs@cug.edu.cn (G.J.); fangcl@cug.edu.cn (C.F.); flyzlingfly@163.com (L.Z.); \\ sjzheng212@cug.edu.cn (S.Z.); 467126878@cug.edu.cn (Y.Y.) \\ 2 Department of Oil and Gas, Saint Petersburg Mining University, 199106 Saint Petersburg, Russia; \\ Leusheva_EL@pers.spmi.ru (E.L.); Morenov@spmi.ru (V.M.) \\ * Correspondence: 1lx1039304620@cug.edu.cn; Tel.: +86-155-2775-8961
}

Received: 27 July 2020; Accepted: 7 September 2020; Published: 9 September 2020 updates

\begin{abstract}
Improving the efficiency of well drilling process in a reservoir is directly related to subsequent well flow rates. Drilling of deviated and horizontal wells is often accompanied by an increase in pressure losses due to flow resistance caused by small size of the annular space. An important role in such conditions is played by the quality of borehole cleaning and transport capacity of drilling fluid, which is directly related to the rheological parameters of the drilling fluid. The main viscosifiers in modern drilling fluids are polymer reagents. They can be of various origin and structure, which determines their features. This work presents investigations that assess the effect of various polymers on the rheological parameters of drilling fluids. Obtained data are evaluated taking into account the main rheological models of fluid flow. However, process of fluid motion during drilling cannot be described by only one flow model. Paper shows experimentally obtained data of such indicators as plastic viscosity, dynamic shear stress, non-linearity index and consistency coefficient. Study has shown that high molecular weight polymer reagents (e.g., xanthan gum) can give drilling fluid more pronounced pseudoplastic properties, and combining them with a linear high molecular weight polymer (e.g., polyacrylamide) can reduce the value of the dynamic shear stress. Results of the work show the necessity of using combinations of different types of polymer reagents, which can lead to a synergetic effect. In addition to assessing the effect of various polymer reagents, the paper presents study on the development of a drilling fluid composition for specific conditions of an oil field.
\end{abstract}

Keywords: polymer reagents; drilling mud; rheology; plastic viscosity; dynamic shear stress; equivalent circulation density

\section{Introduction}

Process of well construction is complex and costly one. Efficiency of the entire hydrocarbon production process depends on applied technological solutions.

Analytical review of scientific and technical literatures in the field of complications and accidents during well construction [1-4], in particular, directional and horizontal wells, shows that to prevent the most frequent complications and accidents, first of all it is necessary to use high-quality drilling mud, which will correspond to geological and technical-technological conditions of drilling.

In recent decades, classic clay compositions have been replaced by more complex polymer solutions [5-8]. Clay solutions can be treated with various additives, for example, acrylic polymers, 
to control the properties of the drilling mud, including rheological characteristics [9]. Polymer reagents can be divided into two groups according to functional features and points of concentration. The first group includes surface-active substances (surfactants), which can be concentrated at the phase's boundary and act as emulsifiers, foaming agents or defoamers, dispersants or wetting agents. Reagents of the second group are in a dispersion medium and affect the technological properties of the drilling fluids. In turn, reagents, which are located in a dispersed medium and affect the technological properties of the drilling fluids, are divided into organic and inorganic. They can change the structure and properties of a dispersed medium, suppress or activate the effect of surfactants, and can also regulate the concentration of hydroxides and bind undesirable ions. Inorganic polymers include silicates, chromates and polyphosphates [10-12].

Organic polymers of natural or synthetic origin are most developed. Such polymers are obtained by chemical processing of natural macromolecular compounds or by synthesis from low molecular weight substances. M.M. Dardir et al. propose to use synthetic reagent (ether) in the composition of the drilling fluid, which has high biodegradability and low toxicity [13]. Polysaccharides, lignosulfonates, tannins, humates are natural polymers; cellulose ether is semi-synthetic and synthetic polymers include petrochemical derivatives such as ethylene oxide and acrylic polymers [9]. F.T.G. Dias et al. show the possibility of using modified starch in non-aqueous drilling fluids [14]. Polymeric reagents are often improved by additional treatment. Work [15] presents the composition of a saline solution based on attapulgite treated with polyacrylamide, in which this reagent improves both rheological and filtration indicators. Authors of this work will investigate the effect of polymer reagents of different origins and structure on the rheological parameters of the drilling fluid.

Rheological properties of the drilling muds affect almost all processes and indicators associated with well drilling; therefore, they are among the most important. In particular, rheological properties to a large extent determine the cleaning degree of well bottomhole from sludge and cooling of rock-cutting tool, transporting ability of the washing fluid, hydraulic resistance in all parts of the circulation system in the well and hydrodynamic pressure on its walls and bottomhole during drilling; amplitude of pressure fluctuations during start-up and stop of the pumps, performing of tripping operations and development of the well with drilling string pacing; intensity of washing fluid enrichment with sludge, etc. [16-18].

Regulation of solutions' rheological properties, continuously changing in the process of deepening, and maintaining them in accordance with requirements of drilling is one of the most important tasks of solution's chemical treatment. Rheological properties of solutions are affected by a large number of variable factors: temperature, pressure, component composition of the solution and concentration of each component, content of high-dispersed and colloidal fractions of clay, rate of shear deformations and thixotropic effects [19]. Choice of a rheological model, by which rheological parameters will be determined, is also important. Analysis of scientific and technical literature on this issue $[11,20,21]$ showed that today there is no rheological model, which could give necessary accuracy of approximation over entire interval of shear rate changes, corresponding to drilling mud circulation in the well. Therefore, accuracy of calculated parameters will depend on both the correctly selected model and its applicability in a particular case. Method developed and presented in the article by R. Wi'sniowski, K. Skrzypaszek and T. Małachowski allows selecting a rheological model for the drilling fluid. Models of Bingham plastic, Casson, Ostwald-de Waele and Newton propose to apply a linear regression method to determine the rheological parameters, and models of Herschel-Bulkley, Vom Berg and Hahn-Eyring propose to apply the non-linear regression method [22]. Hyperbolic model by C. Vipulanandan and A.S. Mohammed predicted the maximum shear stress of the drilling fluid, whereas other two models (Herschel-Bulkley and Casson) studied in this work assumed infinite shear stress tolerance for the drilling fluid [9].

Main polymer reagents used to treat drilling fluids mostly affect the structural and rheological parameters of fluids. As mentioned above, they can be of different origin and structure, which will 
affect the rheological parameters of the drilling fluid and the quality of the entire process of well drilling. Table 1 shows various compositions of polymer drilling fluids and the results of their investigations.

Table 1. Investigation of various compositions for polymer drilling fluids.

\begin{tabular}{|c|c|c|c|}
\hline Drilling Mud Composition & Drilling Mud Function & Results & Reference \\
\hline $\begin{array}{l}\text { Bentonite; } \\
\text { High viscosity polyanionic } \\
\text { cellulose (PAC HV); } \\
\text { Tamarind gum }\end{array}$ & $\begin{array}{l}\text { Preservation of reservoir } \\
\text { permeability }\end{array}$ & $\begin{array}{l}\text { Combinations of tamarind gum, PAC and } \\
\text { bentonite clay produce favorable } \\
\text { rheological properties and optimum fluid } \\
\text { loss at very low concentrations. In addition, } \\
\text { its effect on formation damage is less than } \\
\text { guar gum drilling fluids [23]. }\end{array}$ & $\begin{array}{c}\text { V. Mahto, V.P. } \\
\text { Sharma/Journal of } \\
\text { Petroleum Science and } \\
\text { Engineering } 45(2004) \\
123-128\end{array}$ \\
\hline $\begin{array}{l}\text { Polyacrylamide/clay } \\
\text { nanocomposite; } \\
\mathrm{KCl} \text {; } \\
\text { Xanthan gum (XG); } \\
\text { Pregelatinized starch; } \\
\text { Partially } \\
\text { hydrolyzedpolyacrylamide } \\
\text { (PHPA) }\end{array}$ & $\begin{array}{l}\text { Inhibition of clay rocks } \\
\text { during well drilling and } \\
\text { preservation of the } \\
\text { wellbore walls }\end{array}$ & $\begin{array}{l}\text { Developed drilling fluid formulations have } \\
\text { high salt resistance and contribute to better } \\
\text { inhibition of the high swelling potential } \\
\text { shale formations. The test indicated that } \\
\text { nanocomposite could inhibit swelling and } \\
\text { dispersion of the shales more effectively. } \\
\text { Hence, synthesized nanocomposite may be } \\
\text { used as an additive in water based drilling } \\
\text { fluid system for the drilling of water } \\
\text { sensitive formations [24]. }\end{array}$ & $\begin{array}{l}\text { R. Jain, V. Mahto/Journal } \\
\text { of Petroleum Science and } \\
\text { Engineering } 133 \text { (2015) } \\
\text { 612-621 }\end{array}$ \\
\hline $\begin{array}{l}\text { Bentonite; } \\
\text { PAC; } \\
\text { Cellulosenanoparticles } \\
\text { (CNPs), including cellulose } \\
\text { nanocrystals (CNCs) and } \\
\text { cellulose nanofibers (CNFs) }\end{array}$ & $\begin{array}{l}\text { Improving the quality of } \\
\text { reservoir drilling-in }\end{array}$ & $\begin{array}{l}\text { Low solid fluids were successfully prepared } \\
\text { by using CNPs (i.e., CNCs and CNFs) for } \\
\text { substituting a part of bentonite in the fluid } \\
\text { system. Both the CNC and CNF fluids } \\
\text { exhibited similar pseudoplastic behavior, } \\
\text { due to the excellent shear thinning } \\
\text { characteristics of CNP suspensions. } \\
\text { Rheological and fluid filtration properties } \\
\text { of the CNP fluids could be further } \\
\text { optimized by tailoring size distributions, } \\
\text { concentration, and surface functionality of } \\
\text { CNPs [25]. }\end{array}$ & $\begin{array}{c}\text { K. Song et al./Journal of } \\
\text { Natural Gas Science and } \\
\text { Engineering } 34 \text { (2016) } \\
\text { 1403-1411 }\end{array}$ \\
\hline $\begin{array}{l}\text { Seawater; } \\
{\text { Nano } \mathrm{SiO}_{2}}_{\text {Bentonite; }} \\
\text { Na-CMC; } \\
\text { SMP-2; } \\
\text { PVP K90; } \\
\text { KCl }\end{array}$ & $\begin{array}{l}\text { Drilling in natural gas } \\
\text { hydrate-bearing } \\
\text { sediments }\end{array}$ & $\begin{array}{l}\text { Developed } \mathrm{Nano} \mathrm{SiO}_{2} \text { drilling fluid has } \\
\text { good rheological behavior and inhibition of } \\
\text { shale hydration expansion, acceptable fluid } \\
\text { loss, suitable dynamic plastic ratio and } \\
\text { moderate density at low temperature, } \\
\text { which facilitate the formation of orderly } \\
\text { laminar flow, reasonable fluid pressure and } \\
\text { the stability of the borehole wall, effectively } \\
\text { suspend and carry rock cuttings under a } \\
\text { certain shear rate. Developed Nano } \mathrm{SiO}_{2} \\
\text { drilling fluid has a good ability to inhibit } \\
\text { the formation of hydrates at low } \\
\text { temperature and high pressure [7]. }\end{array}$ & $\begin{array}{c}\text { T. Liu et al./Journal of } \\
\text { Natural Gas Science and } \\
\text { Engineering } 33 \text { (2016) } \\
\text { 934-941 }\end{array}$ \\
\hline $\begin{array}{l}\text { Montmorillonite/attapulgite } \\
\text { mixtures } \\
\text { Polyamine } \\
\text { SDCap } \\
\text { CMC-LV } \\
\text { SD-102 } \\
\mathrm{NaCl} \\
\text { XC (first composition) } \\
\text { SDVis (second recipe) }\end{array}$ & $\begin{array}{l}\text { Drilling wells at low } \\
\text { temperatures }\end{array}$ & $\begin{array}{l}\text { Basic method for the low temperature } \\
\text { rheology control of WBDF is proposed as } \\
\text { follows: First, the development of a } \\
\text { rheology modifier that increases the } \\
\text { rheology at a high temperature, but does } \\
\text { not affect it at a low temperature, and can } \\
\text { help to achieve a flat rheology of WBDF } \\
\text { over a wide temperature range. Second, } \\
\text { optimization of the type, content, size, } \\
\text { and shape of bentonites and weight } \\
\text { materials is important. Third, shortening } \\
\text { the chain length and optimizing the } \\
\text { molecular structure of polymers are } \\
\text { required. Based on this method, two } \\
\text { high-performance WBDFs were optimized; } \\
\text { their rheological properties were more } \\
\text { stable over a wide temperature range from } \\
4 \text { to } 75^{\circ} \mathrm{C}[26] \text {. }\end{array}$ & $\begin{array}{l}\text { X. Zhao et al. Journal of } \\
\text { Petroleum Science and } \\
\text { Engineering } 154 \text { (2017) } \\
\text { 405-416 }\end{array}$ \\
\hline
\end{tabular}

Table 1 shows that use of polymer reagents improves the quality of clay suspensions and allows adjusting the rheological and filtration parameters of drilling fluids. Aim of this work is to study the effect of various polymeric reagents on the rheological parameters of drilling fluids and equivalent 
circulation density. These indicators determine the future permeability and porosity parameters of the reservoir. Therefore, study of this issue is relevant to improve drilling efficiency.

Also relevant is consideration and control of equivalent circulation density (ECD), which takes into account not only hydrostatic pressure of the drilling mud column, but also friction pressure losses, as a result of which hydraulic pressure in the well becomes more than the hydrostatic one.

To calculate pressure that a solution with equivalent circulation density exerts on borehole walls, it is necessary to add pressure losses in the annular space during circulation in the interval from a wellhead to a given depth and hydrostatic pressure of the drilling mud column at the same depth. Resulting pressure will be equal to hydrostatic pressure of solution column with equivalent circulation density [27].

This problem is particularly relevant for horizontal section of the wellbore. Often the geometric dimensions of annular space in the horizontal section of the wellbore are small. The magnitude of pressure losses on local resistances directly depends on geometry of annular space, and the smaller it is, the higher the hydrodynamic pressure. Quality of bottomhole cleaning from sludge and transporting ability of the solution, which is directly related to the rheological parameters of the drilling fluid, plays an important role in such conditions. Poor cleaning will lead to borehole sludging and annular space reduction, which in turn will cause an increase in pressure losses and an increase in ECD [26].

The most efficient way to control ECD is the regulation of rheological parameters of the washing fluid [20]. By changing the rheological parameters of the washing liquid, one can adjust ECD by decreasing or increasing it.

Drilling muds are complex systems that change their rheological parameters and follow different flow laws depending on dispersion medium of the solution, amount of solid phase, presence of polymeric and lubricating additives, temperature, pressure, and shear strain rate. There are several rheological models that are more or less suitable for describing the circulation of the drilling mud in the well. However, all of them allow obtaining rheological parameters with necessary accuracy only on a certain interval of shear strain rates, defined for each model. Wrong choice of mathematical model for determining the rheological parameters of the drilling mud can lead to an error in calculating the equivalent circulation density. Therefore, for a more accurate prediction of $E C D$, it is necessary to understand what law is suitable for movement of liquid. Control and analysis of rheological parameters of drilling muds allows accurately adjusting ECD and avoiding complications in construction process of horizontal wells.

Study of the influence of various polymeric reagents on the rheological properties of drilling fluids, monitoring and analysis of these parameters will allow accurately adjusting the ECD, avoid complications and increase the efficiency of the construction process of deviated and horizontal wells.

The aim of this work is to study the effect of various polymer reagents on the structural and rheological parameters of the drilling fluid, as well as to justify and develop the composition of the drilling mud, which increases efficiency of drilling a horizontal section of the wellbore, taking into account rheological parameters of the drilling mud and equivalent circulation density.

\section{Materials and Methods}

\subsection{Drilling Fluid Rheology}

Drilling fluids used at drilling of oil and gas wells exhibit non-Newtonian behavior: both shear thinning and shear solidification. It is usually believed that in such solutions there is a limiting shear stress and thixotropic effects are present [12]. The first rheological model used to describe rheological behavior of clay suspensions was Bingham-Shvedov or visco-plastic model. It describes substances that, at stresses below a critical value $\tau_{0}$ called the ultimate shear stress or dynamic shear stress, do not deform, but flow at high stresses like viscous liquids $[9,28]$. 
Most drilling fluids are also characterized by the fact that their rheological properties depend both on magnitude of shear stress and on its duration. If viscosity is determined not only by shear rate, but also by shear duration, then such substances are called thixotropic. In thixotropic substances, with an increase in duration of the load, a decrease in viscosity is observed. After the end of deformation process and final rest time, substance regains its initial state.

Despite the fact that Bingham-Shvedov model can be used to describe the behavior of drilling muds flowing inside the pipe at high shear rates, this model cannot be applied to all types of fluids. With appearance of various methods for processing water-based clay muds and with development of non-aqueous drilling fluids, limitations of Bingham model became increasingly apparent [12,20]. Behavior of such drilling muds lies between the boundaries described by Newtonian model and Bingham-Shvedov model. This behavior is called pseudoplastic. Relation between stresses arising in a fluid and the shear rate for pseudoplastic fluids is described by Ostwald-de Waele power-law model.

Like Bingham-Shvedov model, Ostwald-de Waele model does not provide an absolutely accurate characteristic of the drilling mud. However, its use is preferable if drilling mud is treated with polymers or is completely clayless and polymeric. If the fluid flow obeys a power-law model, then the yield and viscosity curves in logarithmic coordinates will be straight lines. In this model, drilling mud is a pseudoplastic fluid that does not have an ultimate dynamic shear stress. Thus, fluid begins to flow immediately after applying a shear load to it [22].

Each of the mentioned above models is applicable only in individual cases. Bingham-Shvedov model includes an indicator of ultimate shear stress, but does not provide an accurate description of solution behavior at low deformation rates. Power-law model, on the contrary, more accurately describes behavior of solution at low shear rates, but due to absence of ultimate shear stress in the model, it cannot describe behavior of solution at extremely low shear rates close to zero. Therefore, behavior of typical drilling muds is between a viscoplastic and a pseudoplastic model.

There are also three-parameter models. Herschel-Bulkley model is obtained by combining a viscoplastic model with the Ostwald-de Waele model and takes into account dynamic shear stress [9].

This model is suitable for describing some of the low-solids drilling muds and solutions treated with polymer reagents. It covers a wider range of shear rates. However, determining the rheological parameters of solutions for this model and integrating the equations of their motion is quite difficult.

It seems more convenient and with acceptable accuracy to use simple Bingham and Ostwald-de Waele models with different rheological parameters for various intervals of shear rates. Often, in calculations, a pseudoplastic model is used with different values of consistency and non-linearity parameters in the shear rate ranges corresponding to the flow in annular space of the well and drilling string. In drilling bit nozzles, the drilling mud can be considered as Newtonian fluid.

\subsection{Justification on Choice of the Research Object}

In order to assess the effect of polymer reagents, it is necessary to determine the object of research. In this paper, it is a drilling fluid for drilling a well in an oil reservoir. This drilling fluid is necessary for drilling a horizontal section of oil wellbore in the reservoir of an oil field located in the Republic of Tatarstan (Russia). Properties of the experimental well are presented in Table 2.

Table 2. Properties of the experimental well.

\begin{tabular}{|c|c|c|c|c|c|}
\hline $\begin{array}{l}\text { Type of } \\
\text { Thewell }\end{array}$ & $\begin{array}{l}\text { Type of the } \\
\text { Formation }\end{array}$ & $\begin{array}{c}\text { Possible } \\
\text { Complications }\end{array}$ & $\begin{array}{l}\text { Temperature of } \\
\text { the Reservoir }\end{array}$ & $\begin{array}{c}\text { Pressure of the } \\
\text { Reservoir }\end{array}$ & Well Design \\
\hline Deviated well & $\begin{array}{l}\text { Sandstones } \\
\text { with mudstone } \\
\text { interseams }\end{array}$ & $\begin{array}{l}\text { Rockslides, } \\
\text { cavings }\end{array}$ & $25^{\circ} \mathrm{C}$ & $12.1 \mathrm{MPa}$ & $\begin{array}{l}\text { Roof of the project } \\
\text { horizon-1196 m, } \\
\text { bottomhole-1208 m, } \\
\text { length-1786 m }\end{array}$ \\
\hline
\end{tabular}

Application of a polymer solution with a low solid phase content (polymerbentonite) is necessary from a depth of $1486 \mathrm{~m}$ along the borehole at drilling for liner placement. At a formation pressure of 
12.1 MPa to ensure necessary backpressure at a given depth, drilling fluid must have a density of at least $1130 \mathrm{~kg} / \mathrm{m}^{3}$.

Selection of optimal rheological properties of the solution is a difficult task. Given the experience of drilling horizontal wells, value of following characteristics should be considered:

- plastic viscosity in the conditions of the specific field;

- dynamic shear stress (DSS), which influences hydrotransport of sludge to the day surface by laminar flow and prevention of weighting agent precipitation in surface circulation system;

- relative viscosity (RV) that is important for timely control of viscosity at drilling site;

- static shear stress (SSS) characterizes the structural and mechanical properties of the solution. Usually it is enough that $\mathrm{SSS}_{10}=5-6 \mathrm{~Pa}, \mathrm{SSS}_{1}=2-3 \mathrm{~Pa}$. At the same time thixotropy coefficient should be in range of 1-1.5;

- water loss (filtration) (F) during drilling in the formation must be minimal to preserve permeability of the reservoir. Absence of filtration is also unacceptable, since in this case a filter cake, which will maintain stability of the reservoir and reduce the coefficient of friction, cannot form on walls of the well that is very important at drilling horizontal section;

- thickness of clay cake (k) should have low friction properties;

- value of $\mathrm{pH}$ defines performance of stabilizer chemicals. The effect is stronger in presence of inorganic inhibitors and mineralizers. Most stabilizer inhibitor reagents are anionic or amphoteric, therefore, for their effective operation, it is necessary to maintain an alkaline environment in the drilling mud.

Thus, taking into account the geological conditions and drilling experience in this field, as well as recommendations from scientific and technical literature, necessary technological properties of the developed solution are presented in Table 3.

Table 3. Necessary technological properties of the drilling mud.

\begin{tabular}{ccccccccc}
\hline Parameter & Density, $\mathbf{k g} / \mathbf{m}^{\mathbf{3}}$ & $\mathbf{R V}, \mathbf{s}$ & $\mathbf{S S S} \mathbf{( 1 / 1 0 ) , \mathbf { P a }}$ & $\mathbf{D S S}, \mathbf{P a}$ & $\mathbf{\eta}, \mathbf{m P a} \cdot \mathbf{s}$ & $\mathbf{F}, \mathbf{c m}^{\mathbf{3}}$ & $\mathbf{k}, \mathbf{m m}$ & $\mathbf{p H}$ \\
\hline Recommended value & $1130( \pm 20)$ & $30-50$ & $3 / 6$ & $1-8$ & $7-20$ & $4-6$ & $1-1.5$ & $8-10$ \\
\hline
\end{tabular}

\subsection{Methods and Equipment}

For research and modification, one of the basic formulations of a polymerbentonite solution with a density of $1140 \mathrm{~kg} / \mathrm{m}^{3}$ used for drilling a horizontal section of the wellbore in a reservoir was selected. Composition of solution is presented in Table 4.

Table 4. Basic composition of polymerbentonite solution.

\begin{tabular}{ccccccccc}
\hline Reagent & Bentonite & NaOH & Starch & Bactericide & CMC-HV & CMC-LV & Chalk & Lubricant \\
\hline Yield, $\mathrm{kg} / \mathrm{m}^{3}$ & 40 & 1 & 15 & 1 & 4 & 1 & 185 & 25 \\
\hline
\end{tabular}

Research considers studying the effect of polymer reagent and modifying the basic composition of washing fluid by replacing the polymer reagent with another or a combination of others, differing from carboxymethyl cellulose (CMC) by molecular weight, structure and properties, in order to improve rheological characteristics, while maintaining other technological parameters within required limits. To find optimal reagent or their combination, it is necessary to study rheological parameters of the drilling mud. Composition, in which rheological parameters will be optimal (for example, such as low values of DSS and non-linearity index), can be considered the most effective and appropriate for use in these conditions.

Effect exerted by polymer reagent depends primarily on its type, structure and molecular weight $[16,20]$. Therefore, various polymeric reagents were selected for study considering their origin and structure: 
- with an average molecular weight (CMC, polyanionic cellulose (PAC)) and high (Xanthan, polyacrylamide (PAA));

- $\quad$ synthetic (PAA) and natural (CMC, PAC, Xanthan);

- $\quad$ anionic (CMC, PAC, Xanthan) and manifesting amphoteric properties (PAA);

- $\quad$ with a linear structure (CMC, PAC, PAA) and branched (Xanthan).

Rheological parameters of drilling muds depend not only on component composition, but also on the shear rate. Therefore, for a deeper analysis of rheological characteristics, their comparison and selection of optimal composition, it is necessary to measure rheological parameters, if possible, on a wider range of shear rates. Different rotation speeds of rotational viscometer correspond to different deformation rates of washing fluid: from low speeds at the beginning of circulation to very high speeds during passing through nozzles of the drilling bit. Measurements were carried out in following ranges of viscometer rotor speeds: $600-400,400-300,300-200,200-100,100-0 \mathrm{rpm}$ [29]. For each range, rheological parameters were determined using a viscoplastic and power-law solution model.

For research, Rheotest RN 4.1 rotational viscometer manufactured by RHEOTEST Medingen $\mathrm{GmbH}$, Germany, was chosen, which automatically registers viscosity and fluidity curves and allows deep rheological description of test medium in wide range of stresses and shear rates. Figure 1 shows a general view of the viscometer Rheotest RN 4.1.

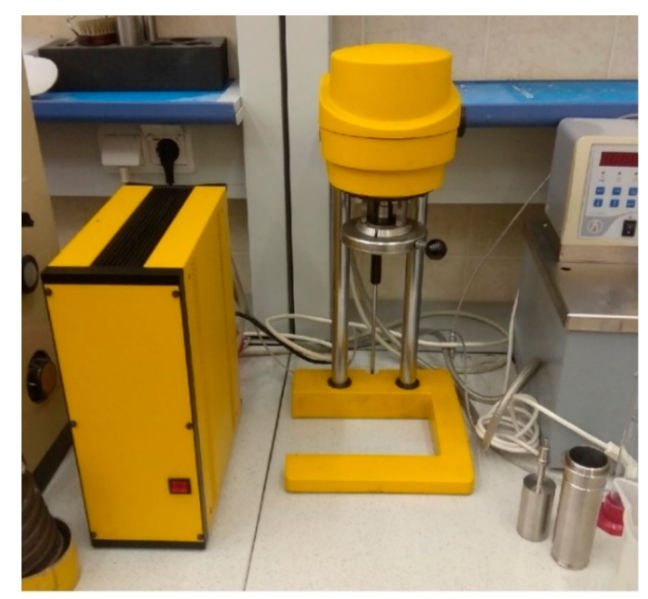

Figure 1. General view of the viscometer Rheotest RN 4.1.

Measuring system with a cylinder of the viscometer is necessary to study rheological characteristics of substances with a viscosity of up to $100,000 \mathrm{mPa} \cdot \mathrm{s}$. It consists of a stationary measuring cup and a cylindrical rotor, which is placed in this cup. To study the behavior of liquids at different temperatures, thermostated vessels are available.

\section{Results and Discussion}

\subsection{Analysis of Obtained Rheological Characteristics and Selection of the Optimal Drilling Mud Formulation}

Rheological parameters of solution with addition of different polymer reagents were measured. Study defined plastic viscosity $(\eta)$, DSS $\left(\tau_{0}\right)$, non-linearity index $(n)$ and consistency coefficient $(K)$. Results are presented in Table 5. 
Table 5. Rheological parameters of investigated solutions.

\begin{tabular}{|c|c|c|c|c|}
\hline Rotation Frequency, rpm & $\eta, \mathrm{mPa} \cdot \mathrm{s}$ & $\tau_{0}, \mathrm{~Pa}$ & $n$ & $\mathbf{K}$ \\
\hline \multicolumn{5}{|c|}{ Rheological parameters of solution 1} \\
\hline $600-400$ & 13.3 & 8.1 & 0.57 & 2.54 \\
\hline $400-300$ & 14.5 & 7.8 & 0.52 & 3.76 \\
\hline $300-200$ & 15.9 & 7.2 & 0.49 & 4.17 \\
\hline $200-100$ & 17.4 & 6.3 & 0.44 & 4.96 \\
\hline $100-0$ & 18.1 & 5.6 & 0.37 & 5.33 \\
\hline \multicolumn{5}{|c|}{ Rheological parameters of solution 2} \\
\hline $600-400$ & 14.1 & 9.4 & 0.55 & 2.82 \\
\hline $400-300$ & 15.5 & 8 & 0.51 & 3.39 \\
\hline $300-200$ & 17.4 & 7.2 & 0.44 & 3.54 \\
\hline $200-100$ & 18.7 & 6.7 & 0.4 & 3.96 \\
\hline $100-0$ & 19.3 & 6.1 & 0.36 & 5.74 \\
\hline \multicolumn{5}{|c|}{ Rheological parameters of solution 3} \\
\hline $600-400$ & 17.7 & 12.2 & 0.36 & 4.37 \\
\hline $400-300$ & 20.3 & 11 & 0.3 & 5.58 \\
\hline $300-200$ & 21.5 & 10.1 & 0.28 & 6.74 \\
\hline $200-100$ & 23.1 & 9.4 & 0.24 & 7.9 \\
\hline $100-0$ & 25.4 & 8.1 & 0.23 & 8.7 \\
\hline \multicolumn{5}{|c|}{ Rheological parameters of solution 4} \\
\hline $600-400$ & 19.3 & 5.6 & 0.55 & 1.3 \\
\hline $400-300$ & 20.9 & 4.7 & 0.51 & 1.8 \\
\hline $300-200$ & 22.1 & 3 & 0.47 & 2.89 \\
\hline $200-100$ & 22.7 & 2.8 & 0.38 & 4.23 \\
\hline $100-0$ & 23.5 & 2.4 & 0.34 & 5.74 \\
\hline \multicolumn{5}{|c|}{ Rheological parameters of solution 5} \\
\hline $600-400$ & 11.2 & 7.3 & 0.45 & 1.5 \\
\hline $400-300$ & 13.5 & 6.9 & 0.41 & 2.63 \\
\hline $300-200$ & 15 & 6.3 & 0.37 & 3.17 \\
\hline 200-100 & 16.7 & 5.4 & 0.32 & 4.49 \\
\hline 100-0 & 17.3 & 4.6 & 0.27 & 4.80 \\
\hline
\end{tabular}

First was the basic composition, which is polymerbentonite solution. Content of polymer reagent: high-viscosity PAC $-4 \mathrm{~g} / \mathrm{L}$, low-viscosity PAC $-1 \mathrm{~g} / \mathrm{L}$. Magnitude of DSS and plastic viscosity is in the required range. With an increase in the shear rate, plastic viscosity of the solution decreases, and the non-linearity index $n$ becomes higher, which indicates the effect of "shear thinning". Experience of well construction and research of processes occurring during circulation of a drilling mud show that it is most advantageous to use pseudoplastic fluids as drilling fluids that have a non-linearity index $n<0.3[18,21]$. Circulation of such a solution in the well provides effective removal of sludge, and resulting hydraulic resistance is minimal, which is very important during drilling-in of the reservoir by a horizontal wellbore. Non-linearity index of solution 1 has a rather low value $n=0.37$.

The second analyzed composition was a solution with the addition of another cellulose ether-polyanionic cellulose. Like CMC, there are high-viscosity and low-viscosity brands. This polymer has a good inhibitory ability in clay rocks. It is widely used in the treatment of clay and clayless drilling muds. Content of polymer reagent: high-viscosity PAC $-4 \mathrm{~g} / \mathrm{L}$, low-viscosity PAC $-1 \mathrm{~g} / \mathrm{L}$. Rheological parameters of the solution with addition of PAC were similar to the parameters of solution 1. All of them are in the required range. Similarity of the results is explained by the fact that these polymeric reagents have a similar linear structure, a slightly different molar mass, and both are anionic polymers. 
Third analyzed composition was a solution with addition of xanthan gum as a polymer reagent. Content of xanthan $-4 \mathrm{~g} / \mathrm{L}$. At the same concentration of the polymer reagent, viscosity of the solution was higher. Values of plastic viscosity and dynamic shear stress were higher than required values. However, non-linearity index turned out to be 0.23 , which indicates that this polymer gave the washing liquid more tangible pseudoplastic properties. These properties are also manifested by a more intensive decrease in plastic viscosity with an increase in shear rate. This is explained by the fact that xanthan gum has a strong difference in structure from cellulose ethers. Firstly, it has a large molecular weight and branched structure, and not linear as in CMC and PAC. Flexibility of macromolecules in linear polymer is always higher than that of branched ones because branched polymers have a large number of short and frequently located side chains, which increase the rigidity of macromolecule due to reduced rotation possibility for individual units relative to each other. Secondly, presence of a larger number of functional groups makes it less mobile due to possible interactions. Such a solution will have higher carrying and cleansing abilities, but the value of hydraulic resistance during circulation will be higher.

Fourth analyzed composition was a solution with addition of PAA as a polymer reagent. Content of PAA-1 $\mathrm{g} / \mathrm{L}$. This composition has similar values of plastic viscosity and a non-linearity index with solutions №1 and №2, however, DSS value was significantly lower. This feature can be explained in terms of the polyacrylamide macromolecule structure. Functional groups in polyacrylamide are attached to the main chain, and are not connected with cyclic groups, like in starch or cellulose ethers. This makes the polyacrylamide macromolecule very flexible, therefore the resistance arising from initiation of washing liquid flow is less and, accordingly, initial shear stress is significantly lower.

Analysis of obtained data revealed that addition of PAA leads to a decrease in the initial shear stress, and addition of xanthan gum gives washing liquid more tangible pseudoplastic properties. Both of these qualities are favorable from a technological point of view. Pseudoplastic properties allow the solution to have high viscosity in the annulus and low viscosity when the fluid flowing in the pipe string and bit nozzles. Lower value of DSS will reduce the amplitude of pressure fluctuations during start-up and stopping of pumps and tripping operations, as well as the likelihood of stagnation zones' formation with accumulation of cuttings in them.

Therefore, the fifth analyzed composition was a solution with simultaneous addition of PAA and xanthan gum. Content of reagents: PAA $-0.5 \mathrm{~g} / \mathrm{L}$, xanthan $-2 \mathrm{~g} / \mathrm{L}$. Thus, in solution 5 , it was possible to simultaneously obtain lower DSS values and more tangible pseudoplastic properties compared to the basic formulation. For a visual representation of differences in rheological characteristics, they are presented on flow and viscosity curves (Figures 2 and 3). Viscometer software allows displaying up to 4 curves on one graph at a time. Therefore, base composition with CMC, solution 3 with xanthan, solution 4 with PAA and solution 5 with PAA and xanthan are chosen for comparison.

Graphs show that solution 5, which contains both PAA and xanthan, will create the least resistance during circulation. Solution 4 with PAA has the lowest initial shear stress, and solution 3 with xanthan, due to its higher molecular weight and branched structure, will thicken the solution more strongly than CMC at the same concentration and have more tangible pseudoplastic properties.

In addition to assessing the effect of polymer reagents on the rheological parameters of the drilling fluid, the aim of the work was to develop a new composition. SSS of drilling mud 5 was measured using the VSN-3 device. $\mathrm{SSS}_{1}=2.3 \mathrm{~Pa}$ and $\mathrm{SSS}_{10}=5.7 \mathrm{~Pa}$. Compliance with the requirements specified in Table 2 of remaining technological properties of solution with considered formulation was also measured. Relative viscosity according to the results of three measurements was $34 \mathrm{~s}$, which corresponds to the necessary requirements. 


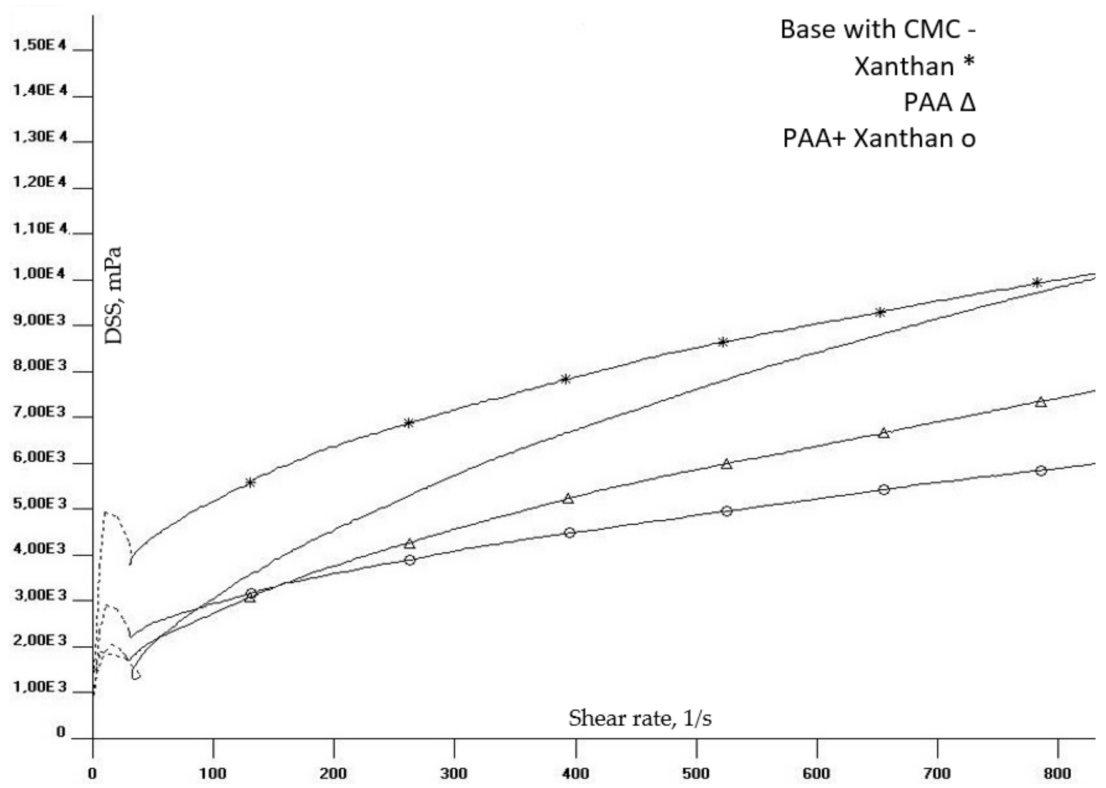

Figure 2. Flow curves in range of 0-400 rpm.

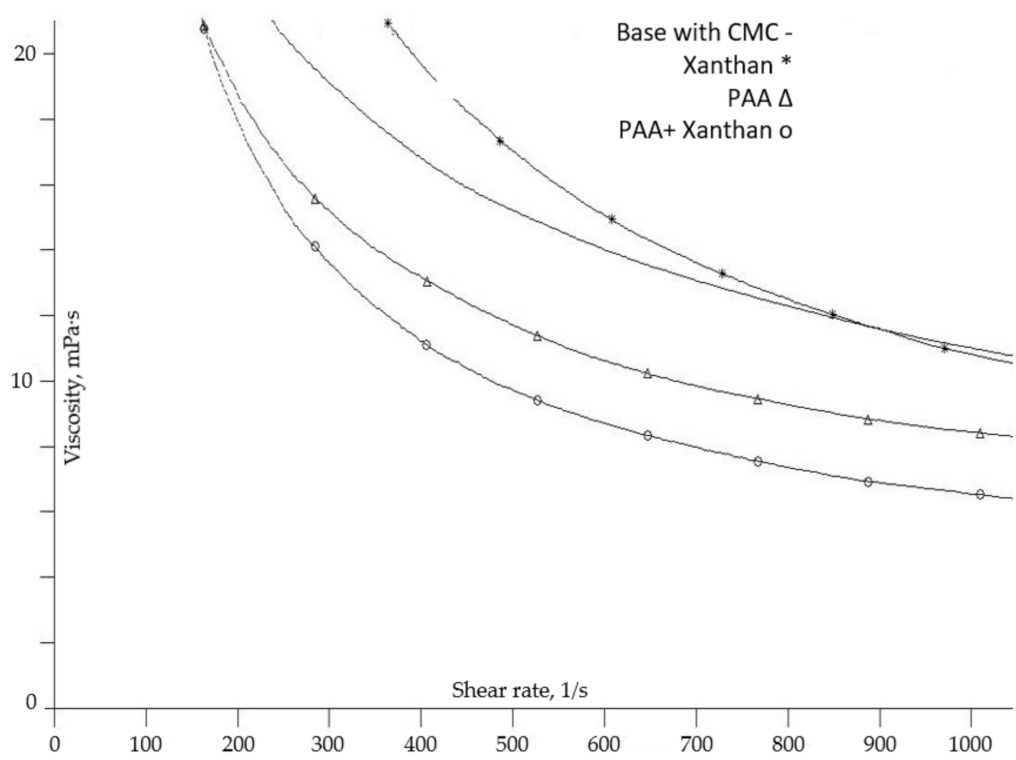

Figure 3. Flow curves in range of 0-500 rpm.

Filtration was measured using a filter press. For $30 \mathrm{~min}$ at an excess pressure of $0.7 \mathrm{MPa}$ [29], the amount of filtered liquid was $5 \mathrm{~cm}^{3}$. Filter cake formed strong and thin (about $1 \mathrm{~mm}$ ).

Coefficient of friction for the filter cake was determined on a KTK-2 device. Angle was 4 degrees, and the tangent was 0.069 , which is a low indicator. It means that resulting filter cake has good lubricity and will help reduce friction at the "steel-rock" interface. This is especially important during drilling directional and horizontal wells.

Level of $\mathrm{pH}$ is 9, which indicates alkaline medium in this drilling mud that is necessary for satisfactory operation of polymer and other reagents.

Technological properties of developed composition of the drilling mud are presented in Table 6.

Table 6. Technological properties of developed composition of the drilling mud.

\begin{tabular}{ccccccccc}
\hline Parameter & Density, $\mathbf{~ k g} / \mathbf{m}^{\mathbf{3}}$ & $\mathbf{R V}, \mathbf{s}$ & $\mathbf{S S S} \mathbf{( 1 / 1 0 ) , ~ P a}$ & $\mathbf{D S S}, \mathbf{P a}$ & $\mathbf{\eta}, \mathbf{m P a} \cdot \mathbf{s}$ & $\mathbf{F}, \mathbf{c m}^{\mathbf{3}}$ & $\mathbf{k}, \mathbf{m m}$ & $\mathbf{p H}$ \\
\hline Recommended value & $1130( \pm 20)$ & $30-50$ & $2-3 / 5-6$ & $1-8$ & $7-20$ & $4-6$ & $1-1.5$ & $8-10$ \\
Acquired value & 1140 & 34 & $2.3 / 5.7$ & $4.6-7.3$ & $11.2-17.3$ & 5 & 1 & 9 \\
\hline
\end{tabular}


Conducted study has shown that various polymer reagents have different effects on rheological properties of the washing fluid. This is due to the difference in their structure and functionality of elementary units. Branched polymer reagents give the washing fluid more tangible pseudoplastic properties. Pseudoplasticity is a necessary property of a modern drilling mud whereas it is necessary to reduce hydraulic resistance at a high deformation rate (bit nozzles and fluid movement in pipes) and increase the holding and transporting ability of the fluid at low shear rates in the annulus. Linear polymers, in which functional units are located at the main circuit, have greater flexibility and create less resistance at movement initiation, which is very important during start-up of pumps and resuming circulation after tripping operations. Performance of polymer reagents largely depends on mineralization of dispersion medium and formation fluids that are in contact with the drilling mud. Presence of functional groups in polymer reagents capable of interaction and dissociation creates the need to control this parameter. High mineralization can lead to the fact that electrostatic repulsion between functional groups is lost, which helps the main polymer chain to be in an extended state (globulization of the polymer reagent). The shape of the polymer reagent chain affects its performance. Reagents rolled into a coil or spiral are less effective.

As a result of the combination of polymer reagents with various properties, it was possible to obtain the composition of the washing liquid with optimal rheological characteristics (Table 7).

Table 7. Optimal composition of the washing liquid.

\begin{tabular}{ccccccccc}
\hline Reagent & Bentonite & NaOH & Starch & Bactericide & PAA & Xanthan & Chalk & Lubricant \\
\hline Yield, $\mathrm{kg} / \mathrm{m}^{3}$ & 40 & 1 & 15 & 1 & 0.5 & 2 & 185 & 25 \\
\hline
\end{tabular}

\subsection{Choice of Mathematical Model}

None of the mathematical models can give an accurate description of rheological characteristics over entire range of shear strain rates, since the behavior of the polymer solution varies greatly at different shear rates $[9,22,28]$. Behavior of real drilling muds lies somewhere between Bingham-Shvedov viscoplastic fluid model and Ostwald-de Waele power-law model. Therefore, accuracy of these mathematical models will be different for different shear rates. To calculate the ECD, one needs to know the rheological parameters of the drilling mud (DSS and plastic viscosity according to viscoplastic model or coefficients $\mathbf{K}$ and $n$ according to power-law model) at low shear rates that correspond to the flow of the drilling mud in annular space. Typically, shear rates of a solution in a drilling string approximately correspond to the shear rates prevailing in a rotational viscometer at rotational frequencies of 300-600 $\mathrm{min}^{-1}$, and shear rates of a solution in an annular space correspond to the shear rates prevailing in a rotational viscometer at rotational frequencies of 6-100 $\mathrm{min}^{-1}$.

Viscometer software allows obtaining flow curves, approximating the data obtained by various mathematical models and comparing the difference between mathematical model and real measurements over entire range of shear rates for this measurement. Therefore, to select a more accurate model and, accordingly, a more correct calculation of the ECD, it is necessary to compare the accuracy of the models at low shear rates of up to $100 \mathrm{~min}^{-1}$. To compare the accuracy of measurements, solution 5 with optimal rheological parameters was chosen. Measurement results are presented in Table 8.

Table 8. Results deviation of measuring rheological characteristics from a mathematical model.

\begin{tabular}{ccc}
\hline Rotation Frequency, rpm & Bingham-Shvedov Viscoplastic Fluid Model & Ostwald-de Waele Pseudoplastic Fluid Model \\
\hline $600-400$ & $7.2 \%$ & $7.8 \%$ \\
$400-300$ & $8.1 \%$ & $6.2 \%$ \\
$300-200$ & $7.4 \%$ & $7.9 \%$ \\
$200-100$ & $9.72 \%$ & $8.1 \%$ \\
$100-0$ & $13.1 \%$ & $5.7 \%$ \\
\hline
\end{tabular}


Thus, at high shear rates, which correspond to rotation frequency of viscometer rotor 300-600 $\mathrm{min}^{-1}$, accuracy of mathematical models is comparable and both can be used to calculate hydraulic losses (during circulation inside the pipe string or if solution passes through the bit nozzles). However, at low shear rates, which correspond to rotational frequencies of $0-100 \mathrm{~min}^{-1}$ (solution flow in annular space), accuracy of power-law model is higher. Therefore, to calculate the ECD, it is most expedient to use rheological parameters of the washing liquid according to a power-law model, namely, consistency coefficient $\mathbf{K}$ and the non-linearity index $n$.

\subsection{Calculation of Equivalent Circulation Density (ECD)}

Equivalent circulation density of the drilling mud takes into account not only hydrostatic pressure of the drilling mud column, but also pressure loss during circulation of the washing fluid through the annular space. Pressure loss in the annular space will be the sum of pressure loss due to friction and pressure loss in local obstacles.

Formulas used to calculate the friction pressure loss in the annular space will depend on flow regime. The following is a calculation of the pressure loss during circulation of a pseudoplastic fluid in an annular space. Upon transition to a turbulent flow regime, frictional pressure losses will begin to increase significantly. Therefore, at first, it is necessary to determine flow regime by comparing actual flow rate of drilling mud $Q$ with the critical $Q_{c r}$. Turbulence of the flow in annular space begins when [30]:

$$
\operatorname{Re}_{\text {cr.an. }}=\frac{4848}{f^{\prime}(n)}
$$

where $R e_{c r . a n .}$-critical Reynolds number for annular space; $f^{\prime}(n)$-Fanning friction factor.

$$
f^{\prime}(n)=\frac{(2 n+1)^{2}}{n} \cdot\left(\frac{1}{2+n}\right)^{\frac{n+2}{n+1}}
$$

where $n$-drilling mud non-linearity index.

Critical flow rate at which the flow goes into turbulent mode is calculated by formula:

$$
Q_{\text {cr.an. }}=\frac{\pi}{4} \cdot\left(D^{2}-d_{e x}^{2}\right) \cdot\left(\frac{\operatorname{Re}_{c r . a n} \cdot K \cdot\left(\frac{2 n+1}{n}\right)^{n}}{12^{1-n} \cdot\left(D-d_{e x}\right)^{n} \cdot \rho}\right)^{\frac{1}{2-n}}
$$

where $D$-well diameter, $\mathrm{m} ; d_{e x}$-drilling string external diameter, $\mathrm{m} ; \rho$-drilling mud density, $\mathrm{kg} / \mathrm{m}^{3} ; K$ - consistency coefficient.

If designed $\mathrm{Q}$ is larger than $Q_{\text {cr.an., }}$ then flow mode is turbulent. Friction pressure losses in the annular space are calculated by the Darcy-Weisbach formula. For this, it is necessary to calculate the value of "reduced" Reynolds number for a power-law fluid by the formula:

$$
\operatorname{Re}_{r d . a n .}=192 \cdot\left(\frac{n}{2 n+1}\right)^{n} \cdot \frac{\rho}{K} \cdot\left(\frac{Q}{\pi}\right)^{2-n} \cdot \frac{1}{\left(D-d_{e x}\right)^{2-2 n} \cdot\left(D+d_{e x}\right)^{2-n}}
$$

Coefficient of hydraulic resistance $\lambda_{a n}$ in the annular space with laminar flow is calculated by the formula:

$$
\lambda_{a n}=\frac{96}{\operatorname{Re}_{\text {rd.an }}}
$$

At turbulent flow—by the formula:

$$
\lambda_{\text {an }}=\frac{0.09}{\operatorname{Re}_{\text {rd.an. }}{ }^{0.125}}
$$


Then pressure losses in the annular space are equal to:

$$
p_{a n}=\lambda_{a n} \cdot \frac{8 Q^{2} l \rho}{\pi^{2} \cdot\left(D-d_{e x}\right)^{3} \cdot\left(D+d_{e x}\right)^{2}}
$$

where $\mathrm{Q}$-drilling mud flow rate, $\mathrm{m}^{3} / \mathrm{s}$; l-length of the well, $\mathrm{m}$;

Local pressure losses at string locks in the annular space are determined from expression:

$$
p_{a n . l}=\frac{l^{\prime \prime}}{l^{\prime}} \cdot\left(\frac{D^{2}-d_{e x}^{2}}{D^{2}-d_{l k}^{2}}-1\right)^{2} \cdot \rho \cdot v_{a n}^{2}
$$

where $l^{\prime}$-average pipe length in a given drilling string section, $\mathrm{m} ; l^{\prime \prime}$ - section length of the drilling pipes with the same diameter, $\mathrm{m}$; $d_{l k}$ - external diameter of the locking joint, $\mathrm{m}$; $v_{a n}$ - upward flow velocity of the solution in the annular space, $\mathrm{m} / \mathrm{s}$.

Having added local pressure losses and friction pressure losses in the annular space, ECD is calculated by the following formula:

$$
\rho_{e q}=\frac{p_{a n \cdot l}+p_{a n}}{g \cdot H}+\rho
$$

where g-acceleration of gravity, $\mathrm{m} / \mathrm{s}^{2} ; \mathrm{H}$-vertical well depth, $\mathrm{m}$.

ECD calculation results are presented in Figure 4.

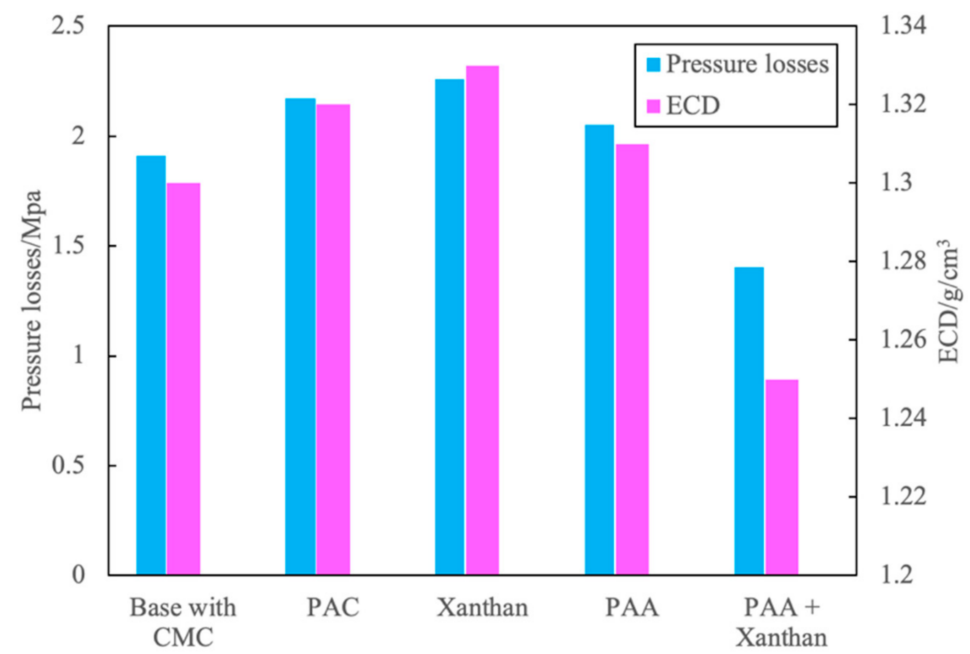

Figure 4. Calculation of ECD using various washing fluid compositions.

Obtained data show that when selecting a structuring agent for a drilling fluid, it is necessary to take into account the rheological parameters of the resulting fluid. Thus, the replacing CMC reagent with a combination of PAA and Xanthan can reduce the ECD by $4 \%$.

\section{Conclusions and Recommendations}

1. Conducted laboratory study has shown that high-molecular polymer reagents (e.g., xanthan gum) can give flushing liquids tangible pseudoplastic properties, and their combination with a linear high-molecular polymer (e.g., PAA) can reduce DSS value. Thus, at selection of polymer reagents, it is necessary to take into account their structure, molecular weight and properties. Combination of different types of reagents can lead to a synergistic effect.

2. Optimal composition of the drilling mud for the conditions of an oil field located in the Republic of Tatarstan (Russia) includes xanthan gum and PAA as polymer reagents. 
3. Calculation of ECD showed the need to consider rheological parameters when selecting polymer reagents for drilling fluids. This is especially important when drilling productive formations, where an increase in the density of the drilling fluid can lead to more severe contamination of the bottomhole zone of the formation and, as a result, to decrease further well production.

Author Contributions: Conceptualization, T.L., G.J. and E.L.; Data curation, L.L.; Formal analysis, E.L. and V.M.; Funding acquisition, T.L. and G.J.; Investigation, E.L.; Methodology, L.L.; Project administration, T.L. and G.J.; Resources, E.L. and V.M.; Software, L.L.; Supervision, L.L. and C.F.; Validation, T.L. and S.Z.; Visualization, Y.Y.; Writing-original draft, E.L.; Writing—review \& editing, T.L., C.F. and L.Z. All authors have read and agreed to the published version of the manuscript.

Funding: This research was funded by Grant of Saint Petersburg Mining University and National Key R\&D Program of China, grant number 2016YFE0204300

Acknowledgments: Authors thank Saint Petersburg Mining University for the enabling of experiments and Jiang for technical support and funding.

Conflicts of Interest: The authors declare no conflict of interest.

\section{Nomenclature}

Q actual flow rate of drilling $\mathrm{mud}, \mathrm{m}^{3} / \mathrm{s}$;

$\mathrm{Q}_{\mathrm{cr}} \quad$ critical flow rate of drilling mud, $\mathrm{m}^{3} / \mathrm{s}$;

$R e_{\text {cr.an. }} \quad$ critical Reynolds number for annular space;

$f^{\prime}(n) \quad$ Fanning friction factor;

$n \quad$ drilling mud non-linearity index;

Qcran. Critical flow rate at which the flow goes into turbulent mode, $\mathrm{m}^{3} / \mathrm{s}$;

d well diameter, $\mathrm{m}$;

$d_{e x} \quad$ drilling string external diameter, $\mathrm{m}$;

$\rho \quad$ drilling mud density, $\mathrm{kg} / \mathrm{m}^{3}$;

$\mathrm{K} \quad$ consistency coefficient;

$R e_{r d . a n .} \quad$ Reynolds number for a power-law fluid;

$\lambda_{a n} \quad$ coefficient of hydraulic resistance;

$p_{a n} \quad$ pressure losses in the annular space, $\mathrm{Pa}$;

$l \quad$ length of the well, $\mathrm{m}$;

$p_{a n . l} \quad$ local pressure losses at string locks in the annular space, Pa;

$l^{\prime} \quad$ average pipe length in a given drilling string section, $\mathrm{m}$;

$l^{\prime \prime} \quad$ section length of the drilling pipes with the same diameter, $\mathrm{m}$;

$d_{l k} \quad$ external diameter of the locking joint, $\mathrm{m}$;

$v_{a n} \quad$ upward flow velocity of the solution in the annular space, $\mathrm{m} / \mathrm{s}$.

$\rho_{\text {eq }} \quad$ equivalent circulation density, $\mathrm{kg} / \mathrm{m}^{3}$;

g acceleration of gravity, $\mathrm{m} / \mathrm{s}^{2}$;

$\mathrm{H} \quad$ vertical well depth, $\mathrm{m}$.

\section{References}

1. Litvinenko, V.S.; Dvoinikov, M.V. Justification of the technological parameters phoice for well drilling by rotary steerable systems. J. Min. Inst. 2019, 235, 24-29. [CrossRef]

2. Litvinenko, V. The Role of Hydrocarbons in the Global Energy Agenda: The Focus on Liquefied Natural Gas. Resources 2020, 9, 59. [CrossRef]

3. Tabatabaee Moradi, S.S.; Nikolaev, N.I. Assessment of the cement failure probability using statistical characterization of the strength data. J. Pet. Sci. Eng. 2018, 164, 182-188. [CrossRef]

4. Moradi, S.S.T.; Nikolaev, N.I.; Chudinova, I.V. Geomechanical Analysis of Wellbore Stability in High-pressure, High-temperature Formations. In Proceedings of the Eage Conference \& Exhibition, Paris, France, 12-15 June 2017.

5. Efficiency Estimation of the Single- and Multicomponent Anti-hydrate Reagents|Journal of Mining Institute. Available online: http://pmi.spmi.ru/index.php/pmi/article/view/13217 (accessed on 24 August 2020). 
6. Wang, R.; Liu, T.; Ning, F.; Ou, W.; Zhang, L.; Wang, Z.; Peng, L.; Sun, J.; Liu, Z.; Li, T. Effect of hydrophilic silica nanoparticles on hydrate formation: Insight from the experimental study. J. Energy Chem. 2018, 30, 98-108. [CrossRef]

7. Liu, T.; Jiang, G.; Zhang, P.; Sun, J.; Sun, H.; Wang, R.; Zheng, M. A new low-cost drilling fluid for drilling in natural gas hydrate-bearing sediments. J. Nat. Gas Sci. Eng. 2016, 33, 934-941. [CrossRef]

8. Pashkevich, M.A.; Alekseenko, A.V.; Petrova, T.A. Application of polymeric materials for abating the environmental impact of mine wastes. J. Phys. Conf. Ser. 2019, 1384, 012039. [CrossRef]

9. Vipulanandan, C.; Mohammed, A.S. Hyperbolic rheological model with shear stress limit for acrylamide polymer modified bentonite drilling muds. J. Pet. Ence Eng. 2014, 122, 38-47. [CrossRef]

10. Khudyakov, G.I. Development of methods of analytical geometry of a sphere for solving geodesy and navigation tasks. Zapiski Gorn. Inst. 2017, 223, 70-81. [CrossRef]

11. Kelessidis, V.C.; Maglione, R.; Tsamantaki, C.; Aspirtakis, Y. Optimal determination of rheological parameters for Herschel-Bulkley drilling fluids and impact on pressure drop, velocity profiles and penetration rates during drilling. J. Pet. Sci. Eng. 2006, 53, 203-224. [CrossRef]

12. Walker, P.R.; Sheikholeslami, R. Assessment of the effect of velocity and residence time in $\mathrm{CaSO} 4$ precipitation flow reaction. Chem. Eng. Sci. 2003, 58, 3807-3816. [CrossRef]

13. Dardir, M.M.; Ibrahime, S.; Soliman, M.; Desouky, S.D.; Hafiz, A.A. Preparation and evaluation of esteramides as drilling fluidsand evaluation of some esteramides as synthetic based drilling fluids. Egypt. J. Petrol. 2014, 23, 34-43. [CrossRef]

14. Dias, F.T.G.; Souza, R.R.; Lucas, E.F. Influence of modified starches composition on their performance as fluid loss additives in invert-emulsion drilling fluids. Fuel 2015, 140, 711-716. [CrossRef]

15. Shettigar, R.R.; Misra, N.M.; Patel, K. CTAB grafted PAM gel and its application in drilling fluid. J. Pet. Ence Eng. 2018, S0920410517308197. [CrossRef]

16. Blinov, P.A.; Dvoynikov, M.V. Rheological and filtration parameters of the polymer salt drilling fluids based on xanthan gum. J. Eng. Appl. Ences 2018, 13, 5661-5664. [CrossRef]

17. Menezes, R.R.; Campos, L.; Ferreira, H.S.; Marques, L.N. Use of statistical design to study the influence of CMC on the Theological properties of bentonite dispersions for water-based drilling fluids. Appl. Clay Sci. 2010, 49, 13-20. [CrossRef]

18. Morenov, V.; Leusheva, E.; Martel, A. Investigation of the fractional composition effect of the carbonate weighting agents on the rheology of clayless drilling mud. Int. J. Eng. 2018, 31, 1152-1158.

19. Zheng, M.; Jiang, G.; Liu, T.; Ning, F.; Zhang, L.; Chikhotkin, V.F. Effect on the performance of drilling fluids at downhole rock surfaces at low temperatures. J. Earth Ence 2016, 27, 856-863. [CrossRef]

20. Hamed, S.B.; Belhadri, M. Rheological properties of biopolymers drilling fluids. J. Pet. Ence Eng. 2009, 67, 84-90. [CrossRef]

21. Grigoriev, B.S.; Eliseev, A.A.; Pogarskaya, T.A.; Toropov, E.E. Mathematical modeling of rock crushing and multiphase flow of drilling fluid in well dilling. J. Min. Inst. 2019, 235, 16-23. [CrossRef]

22. Winiowski, R.; Skrzypaszek, K.; Maachowski, T. Selection of a Suitable Rheological Model for Drilling Fluid Using Applied Numerical Methods. Energies 2020, 13, 3192. [CrossRef]

23. Mahto, V.; Sharma, V.P. Rheological study of a water based oil well drilling fluid. J. Pet. Ence Eng. 2004, 45, 123-128. [CrossRef]

24. Jain, R.; Mahto, V. Evaluation of polyacrylamide/clay composite as a potential drilling fluid additive in inhibitive water based drilling fluid system. J. Pet. Sci. Eng. 2015, 133, 612-621. [CrossRef]

25. Song, K.; Wu, Q.; Li, M.-C.; Wojtanowicz, A.K.; Dong, L.; Zhang, X.; Ren, S.; Lei, T. Performance of low solid bentonite drilling fluids modified by cellulose nanoparticles. J. Nat. Gas Sci. Eng. 2016, 34, 1403-1411. [CrossRef]

26. Zhao, X.; Qiu, Z.; Huang, W.; Wang, M. Mechanism and method for controlling low-temperature rheology of water-based drilling fluids in deepwater drilling. J. Pet. Sci. Eng. 2017, 154, 405-416. [CrossRef]

27. Dokhani, V.; Ma, Y.; Yu, M. Determination of equivalent circulating density of drilling fluids in deepwater drilling. J. Nat. Gas Ence Eng. 2016, 34, 1096-1105. [CrossRef]

28. Livescu, S. Mathematical modeling of thixotropic drilling mud and crude oil flow in wells and pipelines-A review. J. Pet. Ence Eng. 2012, 98-99, 174-184. [CrossRef] 
29. Standards, B. Petroleum and Natural Gas Industries—Drilling Fluid Materials—Specifications and Tests; NE-EN ISO 13500/A1-2011. 2008. Available online: https://www.iso.org/standard/46560.html (accessed on 24 August 2020).

30. Siginer, D. Hydromechanics of Partially Penetrating Wells; Technical University of Istanbul Press: Istanbul, Turkey, 1971. 